\title{
Rootstocks Modify Scion Architecture, Endogenous Hormones, and Root Growth of Newly Grafted 'Royal Gala' Apple Trees
}

\author{
Ben van Hooijdonk ${ }^{1,2}$, David Woolley, and Ian Warrington \\ Institute of Natural Resources, Massey University, Private Bag 11 222, Palmerston North, \\ New Zealand \\ Stuart Tustin \\ The New Zealand Institute for Plant \& Food Research Ltd., Hawke's Bay, Private Bag 1401, Havelock \\ North, New Zealand
}

\begin{abstract}
AdDitional INDex words. Malus $\times$ domestica, dwarfing, indole-3-acetic acid, cytokinin, gibberellin
Abstract. 'Royal Gala' apple scions (Malus $\times$ domestica) were grafted onto 1-year-old rootstock stools of 'M.9' (M.9), 'M.M.106' (MM.106), 'Merton 793' (M.793), and 'Royal Gala' [R.G (control)] to elucidate how the dwarfing apple rootstock (M.9) modified scion architecture, the time from grafting when this started, and whether changes in scion architecture were explained by some endogenous hormones present within the scion. At the end of the first season of growth (April), the final length and node number of the primary shoot were similar for scions on M.9 and R.G. However, M.9 appeared to limit the number of secondary shoots formed on the primary shoot during summer. In addition, the proportion of secondary shoots that were actively extending in fall was lower for M.9; consequently, the final mean length of the secondary shoots was slightly shorter for M.9 compared with R.G. Collectively, these subtle effects of M.9 significantly reduced the final total shoot length of the scion compared with R.G. The final dry weight of the scion and root system was also lower for M.9 than MM.106, M.793, and R.G. The mean rate of indole-3-acetic acid diffusing from the apex of the primary shoot progressively declined from February onward irrespective of rootstock, whereas the mean concentration of zeatin riboside $(\mathrm{ZR})$ in the xylem sap increased during the same period, and these events appeared to coincide with cumulative increases in the number of axillary growing points formed on the scion. Despite this general trend, M.9 had a greater concentration of ZR in the xylem sap during February compared with R.G, but the primary shoot on M.9 did not develop more axillary growing points, indicating that other endogenous hormonal signals were also involved in regulating scion branching. By March, M.9 lowered gibberellin A19 (GA, concentration in the xylem sap of the scion significantly compared with R.G. We conclude that dwarfing apple rootstocks may limit root-produced $\mathrm{GA}_{19}$ supplied to shoot apices of the scion, where $\mathrm{GA}_{19}$ may be a precursor of bioactive gibberellin $\mathrm{A} 1$ required for shoot extension growth.
\end{abstract}

Elucidating how dwarfing apple rootstocks modify scion architecture and the precise time after propagation when this first starts is essential to identify clearly those processes that are the first physiological causes of rootstock-induced scion dwarfing from those that are subsequent developmental effects. In the first year of growth after propagation of the composite tree, M.9 modified scion architecture by reducing the mean length (Cannon, 1941; Rao and Berry, 1940) and node number (Costes et al., 2001; van Hooijdonk et al., 2010) of the primary shoot. In addition, fewer axillary buds on the primary shoot tended to grow out; thus, fewer secondary shoots formed (Jaumien et al., 1993; van Hooijdonk et al., 2010). In contrast, others reported that, irrespective of rootstock vigor, the final mean length of the primary shoot was similar at the end of the first year of growth after propagation of the composite tree (Seleznyova et al., 2008; Tukey and Brase, 1941). Subsequently, scion vigor was first reduced by the dwarfing apple rootstock in Year 2, after it increased flowering of the scion (Seleznyova et al., 2008). Thus, dwarfing apple rootstocks appear to initially modify scion

Received for publication 13 May 2010. Accepted for publication 24 Jan. 2011. ${ }^{1}$ Current address: The New Zealand Institute for Plant \& Food Research Ltd., Hawke's Bay, Private Bag 1401, Havelock North, New Zealand.

${ }^{2}$ Corresponding author. E-mail: Ben.vanHooijdonk@plantandfood.co.nz. architecture in either the first or early in the second year of growth after propagation of the composite tree.

Lockard and Schneider (1981) hypothesized that dwarfing apple rootstocks control scion vigor by reducing the basipetal transport of indole-3-acetic acid (IAA) from scion to root that limits root growth and/or cytokinin biosynthesis and consequently the amount of root-produced cytokinin supplied to the scion in the xylem vasculature. In support of this hypothesis, cytokinins were identified in the xylem sap of apple trees (Jones, 1973; Kamboj et al., 1999a), and 'Fiesta' scions on M.9 contained a lower total concentration of zeatin (Z) plus ZR in their xylem sap than scions on MM.106 (Kamboj et al., 1999a). Atkinson et al. (2003) reported that the graft union of a composite apple tree may also contribute to rootstock-induced scion dwarfing by limiting the movement of water, nutrients, and hormones into the scion. However, the total concentration of cytokinins in the xylem sap of composite trees on a dwarfing apple rootstock was similar above (i.e., in scion xylem sap) or below (i.e., in root exudate) the graft union (Kamboj et al., 1999a). Thus, it appears the root system rather than the graft union is the primary part of the M.9 rootstock responsible for limiting the supply of cytokinins to the scion.

A lower amount of root-produced cytokinins supplied to the scion on a dwarfing apple rootstock was postulated to limit shoot extension growth of the scion (Jones, 1973; Kamboj et al., 
1999a; Lockard and Schneider, 1981). Indeed, Jones (1973) showed that cytokinin stimulated the outgrowth of rootless apple shoots in vitro. Kamboj et al. (1999a) also reported that increased rates of shoot extension growth for composite apple trees on vigorous rootstocks may be explained because of a higher total concentration of cytokinins in the xylem sap of their scion; however, their study presented no shoot growth data to support this hypothesis. If endogenous cytokinins do regulate shoot extension growth of the scion, it would be reasonable to expect exogenous cytokinins to stimulate the development of longer annual shoots. When applied to the scion of young composite apple trees, benzylaminopurine (BAP) did not stimulate longer primary (Wertheim and Estabrooks, 1994) or secondary shoots (Popenoe and Barritt, 1988). Rather, BAP stimulated axillary buds along the primary shoot to break and form secondary shoots (Kender and Carpenter, 1972; van Hooijdonk et al., 2010; Williams and Stahly, 1968). Thus, a lower endogenous concentration of cytokinins in the xylem sap of the scion on M.9 (Kamboj et al., 1999a) may contribute to scion dwarfing by limiting the total number of axillary growing points (i.e., spurs + shoots) that form on the primary shoot.

Dwarfing apple rootstocks are also reported to limit scion vigor by increasing the proportion of annual shoots that end extension growth early during the growing season (Robitaille and Carlson, 1976; van Hooijdonk et al., 2010). Unlike cytokinins, gibberellin(s) applied to apple scions stimulated shoot extension growth (Robitaille and Carlson, 1976; Sironval et al., 1962; van Hooijdonk et al., 2010) and increased the proportion of annual shoots that grew late in the season (Luckwill and Silva, 1979). Gibberellins were found in the xylem sap of apple trees (Jones and Lacey, 1968; Motosugi et al., 1996), indicating that apple roots also synthesize and supply gibberellins to the scion. Compared with vigorous rootstocks, dwarfing rootstocks had lower endogenous concentrations of gibberellin-like substances within the root (Yadava and Lockard, 1977), xylem sap (Ibrahim and Dana, 1971), and leaves or shoots (Fontana-Degradi and Visai, 1978). Listed in order of most to least abundant, the xylem sap of apple trees was reported to contain gibberellin A19, gibberellin A53 ( $\left.\mathrm{GA}_{53}\right)$, gibberellin A23 $\left(\mathrm{GA}_{23}\right)$, gibberellin A44 $\left(\mathrm{GA}_{44}\right)$, gibberellin A15 $\left(\mathrm{GA}_{15}\right)$, gibberellin A17 ( $\left.\mathrm{GA}_{17}\right)$, and gibberellin A18 ( $\left.\mathrm{GA}_{18}\right)$ (Motosugi et al., 1996). These gibberellins are biologically inactive, but forms like $\mathrm{GA}_{19}$ are readily converted to gibberellin A20 $\left(\mathrm{GA}_{20}\right)$ by GA 20-oxidase and, subsequently, $\mathrm{GA}_{20}$ converted to bioactive gibberellin $\mathrm{A} 1\left(\mathrm{GA}_{1}\right)$ by gibberellin 3-oxidase (Yamaguchi, 2008). For apple, suppression of gibberellin 20-oxidase in the shoot of 'Greensleeves' grown on its own roots increased the endogenous concentration of $\mathrm{GA}_{19}$ in the shoot apex but lowered concentrations of $\mathrm{GA}_{20}$ and $\mathrm{GA}_{1}$ (Bulley et al., 2005). Shoot apices of the scion may therefore convert $\mathrm{GA}_{19}$ to bioactive $\mathrm{GA}_{1}$. Hence, $\mathrm{GA}_{19}$ might be an important rootproduced signal regulating scion vigor. Presently, it is unknown whether different size-controlling apple rootstocks modify $\mathrm{GA}_{19}$ concentration within the xylem sap of the scion.

Objectives of this study were to elucidate how M.9 modified scion architecture after tree grafting, the precise time when these modifications started, and the possible functional growth relationships occurring between the developing root and scion. Endogenous $\mathrm{GA}_{19}$ in the xylem sap of the scion was measured during the growing season to assess whether its concentration explained likely rootstock differences in the proportion of annual shoots that ended growth early; cytokinins were quantified to determine if their concentrations related to branching of the scion. Rates of IAA diffusing from the apex of 'Royal Gala' primary shoots on different size-controlling rootstocks were also measured to further understand possible shoot-root-shoot relationships between shoot-produced IAA and root-produced cytokinins present in the xylem sap.

\section{Materials and Methods}

Site, tree material, and Cultural management. An experiment was conducted during the 2005-2006 growing season at the Plant Growth Unit, Massey University, Palmerston North, New Zealand. On 1 Sept. 2005, 'Royal Gala' scions were cleft-grafted at a height of $350 \mathrm{~mm}$ onto 30 1-year-old rootstock stools of M.9 [clone 'NZ9' (dwarf)], MM.106 (semidwarf), M.793 (vigorous), and R.G (very vigorous, self-rooted control). The root systems of newly grafted trees were bedded into moist sawdust immediately after grafting. Trees were subsequently planted into $50-\mathrm{L}$ black polythene bags on 20 Sept., placed outside on a weed mat, and arranged as a single row. Planting height was standardized for each tree to leave $150 \mathrm{~mm}$ of rootstock stem above the surface of the growing medium. The growing medium was a mixture of 1 bark:1 pumice (by volume) containing $3 \mathrm{~g} \cdot \mathrm{L}^{-1} 14$-month slow-release fertilizer [15N-4P-7.5K (Osmocote; Scotts, Marysville, OH)]. Supplementary fertilizer [10N-13P-17K (Peters Professional; Scotts $)]$ was dissolved in water $\left(2 \mathrm{~g} \cdot \mathrm{L}^{-1} \mathrm{H}_{2} \mathrm{O}\right)$, and $1 \mathrm{~L}$ of this solution was applied manually to the growing medium of each tree every $14 \mathrm{~d}$. The irrigation system consisted of a $19-\mathrm{mm}$ polytube line to which pressure-compensating minisprinklers were attached (one $4-\mathrm{L} \cdot \mathrm{h}^{-1}$ minisprinkler per tree). Irrigation was scheduled daily for $1 \mathrm{~h}$ at dawn and dusk using an automated time controller (Smart Valve Controller; Hunter, San Marcos, CA). In mid-October, scions were debudded to a single shoot and thereafter received no pruning.

Measurements of TREe GROWTH AND SAMPle COLlection. Six trees per rootstock were randomly selected for destructive harvest on 12 Dec., 9 Jan., 9 Feb., 6 Mar., and 6 Apr. At each harvest, the diameter (D) of the primary shoot was measured $20 \mathrm{~mm}$ from its base with digital calipers, and shoot cross-sectional area (SCA) was calculated as $\pi \mathrm{D}^{2} / 4$. Measurements of shoot lengths and node numbers began at the shoot base and ended at the first unfurled leaf at the shoot apex. The number of spurs (less than $25 \mathrm{~mm}$ with minimal internode extension) and secondary shoots ( $25 \mathrm{~mm}$ or greater with internode extension) arising from axillary buds on the primary shoot were also counted. The term "axillary growing points" is used to describe the total number of both spurs and secondary shoots formed per scion. At the March and April harvests, the percentage of secondary shoots that had ended extension growth was calculated for each tree replicate by dividing its number of secondary shoots that had terminated in a terminal bud by its total number of secondary shoots $\times 100$.

To measure the diffusion of IAA, the apex of each primary shoot was excised $20 \mathrm{~mm}$ beneath its tip to leave two small unfurled leaves per apex. The basal $5 \mathrm{~mm}$ of the shoot apex was placed immediately into $700 \mu \mathrm{L}$ 2-(N-morpholino)ethanesulfonic acid (M3671; Sigma-Aldrich, St. Louis, MO) buffer solution [0.05 mol. $\mathrm{L}^{-1}, \mathrm{pH} 6.2$ ( $\mathrm{Li}$ and Bangerth, 1999)] contained in a $1.5-\mathrm{mL}$ polypropylene microcentrifuge tube (with the lid remaining open). Samples were then placed in a dark room with an air conditioning unit operating to maintain a constant air temperature of $25^{\circ} \mathrm{C}$. An automated misting unit (505; 
Defensor, Zurich, Switzerland) was used to maintain high humidity. After $10 \mathrm{~h}$ of incubation, the base of each apex was recut with a sharp scalpel before being placed into fresh buffer solution. The bases of shoot apices were recut at $10 \mathrm{~h}$ to expose fresh phloem tissue, thereby sustaining IAA diffusion into the buffer by minimizing any phloem blockage that may have resulted from wound healing responses. At $20 \mathrm{~h}$, apices were removed from buffer solutions, buffer solutions from both time periods were pooled for each treatment $\times$ replicate, and stored at $-75{ }^{\circ} \mathrm{C}$ until analysis. Immediately after excision of the apex from the primary shoot, scions were stripped of their leaves and axillary shoots before the primary shoot was severed directly above the graft union. Xylem sap was extracted from the primary shoot under vacuum (Bollard, 1953) and stored at $-20{ }^{\circ} \mathrm{C}$ until analysis. The root system of each tree was washed to remove the growing medium. To obtain the total root length of each root system, fine (less than $2 \mathrm{~mm}$ in diameter) and coarse roots (greater than $2 \mathrm{~mm}$ in diameter) were measured using either a root length scanner (Commonwealth Aircraft Corp., Melbourne, Australia) or a ruler, respectively. Roots, leaves, and stems were oven-dried at $70{ }^{\circ} \mathrm{C}$ to a constant weight.

Quantification of Indole-3-ACETIC ACID. Sep-Pak ${ }^{\circledR} \mathrm{C}_{18}$ columns (Waters, Milford, MA) were each preconditioned sequentially with $5 \mathrm{~mL} 100 \%, 50 \%, 15 \%$, and $0 \%$ solutions (v/v) of methanol and $0.1 \mathrm{~mol} \cdot \mathrm{L}^{-1}$ formic acid. Each sample of IAA diffusate was spiked with $250 \mathrm{~Bq}$ carboxyl-labeled IAA methyl ester $\left({ }^{14} \mathrm{C}\right.$-IAA-Me $)$ as an internal standard before adsorption onto a preconditioned $\mathrm{C}_{18}$ column. The ${ }^{14} \mathrm{C}$-IAAMe internal standard was synthesized by methylating carboxyllabeled IAA (Sigma-Aldrich) with ethereal diazomethane. Each $\mathrm{C}_{18}$ column was eluted with $5 \mathrm{~mL} 15 \%$ methanol before IAA and ${ }^{14} \mathrm{C}$-IAA-Me was removed from the $\mathrm{C}_{18}$ in $5 \mathrm{~mL}$ methanol. Methanol was evaporated to dryness under vacuum, and samples were resuspended in starting solvent [20\% acetonitrile: $80 \% \quad 0.04 \mathrm{~mol} \cdot \mathrm{L}^{-1}$ acetic acid solution $(\mathrm{v} / \mathrm{v})$ adjusted to $\mathrm{pH} 3.38$ with triethylamine (TEA)] before highperformance liquid chromatography (HPLC).

HPLC of hormones was made using an octadecyl silica (ODS) column $(220 \times 4.6 \mathrm{~mm}$ i.d. $)$ in line with an ODS guard column $(3 \times 4.6 \mathrm{~mm}$ i.d.) (Brownlee Spheri-5; Applied Biosystems, Foster City, CA). Solvent was delivered to the column at $1 \mathrm{~mL} \cdot \mathrm{min}^{-1}$ using a Waters 501 and a Waters 510 HPLC pump controlled by an automated gradient controller. Solvents were HPLC-grade acetonitrile and TEA; their elution gradient was: $20 \%$ acetonitrile from 0 to $14 \mathrm{~min}, 40 \%$ acetonitrile from 15 to $20 \mathrm{~min}$, and $98 \%$ acetonitrile from 22 to 25 min returning to $20 \%$ acetonitrile at $30 \mathrm{~min}$.

During HPLC of diffusate samples, a scanning florescence detector (Waters 474) was used to quantify IAA (Crozier et al., 1980) at a retention time of $14.26 \mathrm{~min}$. The limit of quantitation for IAA measured by florescence detection was $1 \mathrm{ng}$; the standard curve produced (10 to $100 \mathrm{ng})$ was linear $\left(r^{2}=0.99\right)$. Before HPLC of diffusate samples, the retention time of ${ }^{14} \mathrm{C}$ IAA-Me was established (24.30 min) using a flow-through radioactivity detector ( $\beta$ Ram; In/Us systems, Tampa, FL). During HPLC of samples, ${ }^{14} \mathrm{C}$-IAA-Me within each diffusate sample was collected based on its known retention time. Because the radioactivity detector was not used during HPLC of diffusate samples, collected fractions of ${ }^{14} \mathrm{C}$-IAA-Me were taken to a liquid scintillation counter (Tri-Carb 2900TR; PerkinElmer, Boston, MA) to count their radioactivity. The recovery of radioactivity within each sample was used to correct for losses of endogenous IAA incurred during purification. Average recovery of ${ }^{14} \mathrm{C}$-IAA-Me was $70 \%$.

QuANTIFICATION OF CYTOKININS AND GIBBERELLINS. Sep-Pak ${ }^{\circledR}$ $\mathrm{C}_{18}$ columns were each preconditioned sequentially with $5 \mathrm{~mL}$ $100 \%, 50 \%, 10 \%$, and $0 \%$ solutions of methanol and 0.1 $\mathrm{mol} \cdot \mathrm{L}^{-1}$ formic acid ( $\left./ \mathrm{v}\right)$. Before adsorption onto a $\mathrm{C}_{18}$ column, xylem sap $(\approx 5 \mathrm{~mL})$ was spiked with $333 \mathrm{~Bq}$ tritiated dialcohols of ZR ( $\left[{ }^{3} \mathrm{H}\right]$-ZR-dialcohol) and isopentenyladenosine $\left(\left[{ }^{3} \mathrm{H}\right]\right.$ IPA-dialcohol) (synthesized by Currie, 1997) and $50 \mathrm{ng}$ deuterium-labeled $\mathrm{GA}_{19}\left(\left[{ }^{2} \mathrm{H}_{2}\right] \mathrm{GA}_{19}\right)$ (purchased from Olchemim Ltd., Olomouc, Czech Republic) as internal standards. Each column was eluted with $5 \mathrm{~mL} 0.1 \mathrm{~mol} \cdot \mathrm{L}^{-1}$ formic acid before cytokinins and the gibberellin were recovered from the $\mathrm{C}_{18}$ in $5 \mathrm{~mL}$ methanol.

For cytokinin ribotides, the $5 \mathrm{~mL}$ of $0.1 \mathrm{~mol} \cdot \mathrm{L}^{-1}$ formic acid used to wash the $\mathrm{C}_{18}$ after loading of the sap sample was collected and incubated with phosphatase to convert ZR-5monophosphate and IPA-5-monophosphate to ZR and IPA, respectively. In short, the $5 \mathrm{~mL}$ of $0.1 \mathrm{~mol} \cdot \mathrm{L}^{-1}$ formic acid was spiked with $333 \mathrm{~Bq}\left[{ }^{3} \mathrm{H}\right]-Z R$-dialcohol and $\left[{ }^{3} \mathrm{H}\right]-$ IPA-dialcohol, dried in a vacuum freeze drier, resuspended in $1 \mathrm{~mL} 20$ $\mathrm{mmol} \cdot \mathrm{L}^{-1}$ Tris buffer ( $\mathrm{pH}$ 9.8) containing 5 units alkaline phosphatase (P552; Sigma-Aldrich) and incubated at $37{ }^{\circ} \mathrm{C}$ for $4 \mathrm{~h}$ in a water bath. After incubation, each sample was adsorbed onto a preconditioned $\mathrm{C}_{18}$ column, the $\mathrm{C}_{18}$ was eluted with $5 \mathrm{~mL} 0.1 \mathrm{~mol} \cdot \mathrm{L}^{-1}$ formic acid, and $\mathrm{ZR}$ and IPA were recovered from $\mathrm{C}_{18}$ in $5 \mathrm{~mL}$ methanol.

Each fraction of methanol was dried under vacuum, resuspended in HPLC starting solvent ( $6 \%$ acetonitrile), and separated with the aforementioned HPLC and solvent system described for IAA. The solvent gradient for cytokinins was: $9 \%$ acetonitrile from 0 to $15 \mathrm{~min}, 27 \%$ acetonitrile from 20 to $30 \mathrm{~min}$, and $95 \%$ acetonitrile from 35 to $40 \mathrm{~min}$ returning to $9 \%$ acetonitrile at $45 \mathrm{~min}$. Endogenous Z, ZR, IPA, or isopentenyladenine (2iP) were collected from the HPLC between 11 to 14 min, 18 to $21 \mathrm{~min}, 27$ to $28 \mathrm{~min}$, or 30 to $33 \mathrm{~min}$, respectively. These elution times for endogenous cytokinins were established previously using authentic cytokinin standards (SigmaAldrich), the aforementioned HPLC and solvent gradient, and a programmable ultraviolet detector (Waters 490E) set at 268 $\mathrm{nm}$. The $\left[{ }^{3} \mathrm{H}\right]$-ZR-dialcohol and $\left[{ }^{3} \mathrm{H}\right]$-IPA-dialcohol internal standards were also collected during HPLC as separate fractions between 9 to $11 \mathrm{~min}$ and 21 to $23 \mathrm{~min}$, respectively. To determine the losses of cytokinins that occurred during chromatography, fractions of $\left[{ }^{3} \mathrm{H}\right]$-ZR-dialcohol and $\left[{ }^{3} \mathrm{H}\right]-\mathrm{IPA}-$ dialcohol were taken to a liquid scintillation counter and counted for radioactivity. Average recovery of the $\left[{ }^{3} \mathrm{H}\right]-\mathrm{ZR}$ dialcohol and $\left[{ }^{3} \mathrm{H}\right]$-IPA-dialcohol internal standard was $70 \%$ and $71 \%$, respectively.

HPLC fractions containing endogenous Z, ZR, IPA, or $2 \mathrm{iP}$ were quantified by radioimmunoassay (RIA) using the methodology described by MacDonald et al. (1981) and Weiler (1980). RIA of Z and ZR or IPA and 2iP used polyclonal antiseras to ZR or IPA, respectively. The antiseras, $\left[{ }^{3} \mathrm{H}\right]-\mathrm{ZR}$ dialcohol, and $\left[{ }^{3} \mathrm{H}\right]-$ IPA-dialcohol, used in the RIA were synthesized at Massey University by Currie (1997). The RIA was most sensitive between $0.03 \mathrm{pmol}$ and $60 \mathrm{pmol}$ of $\mathrm{Z}, \mathrm{ZR}$, IPA or 2iP; the standard curves generated were linear $\left(r^{2}=0.99\right)$ following logit transformation (Currie, 1997). For each sap sample, the concentration of endogenous $\mathrm{Z}$ and $\mathrm{ZR}$ quantified by the RIA was corrected for losses estimated from the recovery of the $\left[{ }^{3} \mathrm{H}\right]-Z R$-dialcohol standard in that sample; the recovery 
of $\left[{ }^{3} \mathrm{H}\right]$-IPA-dialcohol was used to correct IPA and 2iP concentrations.

To determine the retention time of gibberellin, $500 \mathrm{ng} \mathrm{\textrm {GA } _ { 1 9 }}$ (Olchemim Ltd.) was injected into the same HPLC and solvent gradient described for cytokinins, and 1-min fractions were collected. Fractions were dried under vacuum and then dissolved in a $1: 1$ solution $(\mathrm{v} / \mathrm{v})$ of acetonitrile and $0.01 \mathrm{~mol} \cdot \mathrm{L}^{-1}$ ammonium acetate. Each fraction was then manually injected into a single quadrapole mass spectrometer with an electrospray interface (MicroMass; Waters). Flow rate of sample into the mass spectrometer was $100 \mu \mathrm{L} \cdot \mathrm{min}^{-1}$. Cone and capillary voltage were $+30 \mathrm{~V}$ and $+3 \mathrm{kV}$, respectively. Source and dissolvation temperatures were 100 and $250^{\circ} \mathrm{C}$, respectively. Nitrogen was used as both dissolvation gas $\left(400 \mathrm{~L} \cdot \mathrm{h}^{-1}\right)$ and cone gas $(50$ $\left.\mathrm{L} \cdot \mathrm{h}^{-1}\right)$. Each fraction was scanned in negative ionization mode to determine the presence of the ion for the $\mathrm{GA}_{19}$ standard $(\mathrm{m} / \mathrm{z}$ 361). The $\mathrm{GA}_{19}$ standard was present in fractions collected between 28 to $30 \mathrm{~min}$; hence, endogenous $\mathrm{GA}_{19}$ in the xylem sap samples was collected from our HPLC between these times. HPLC fractions containing $\left[{ }^{2} \mathrm{H}_{2}\right] \mathrm{GA}_{19}$ and endogenous $\mathrm{GA}_{19}$ were dried of solvent, methylated with diazomethane, and then silylated with N-methyl-N-(trimethyl-silyl)-trifluoroacetamide (M7891; Sigma-Aldrich) to produce gibberellin methyl esters trimethylsilyl ethers $\left({ }^{2} \mathrm{H}_{2}\right] \mathrm{GA}_{19}$-MeTMSi and $\mathrm{GA}_{19}$-MeTMSi) (Croker et al., 1990). Gibberellin-MeTMSi was injected $(2 \mu \mathrm{L})$ into a gas chromatograph (GC-2010; Shimadzu, Kyoto, Japan) connected to a mass spectrometer (GC-MSQP2010; Shimadzu). The carrier gas was helium at a flow of $1.3 \mathrm{~mL} \cdot \mathrm{min}^{-1}$. Sample separation was made on a capillary column $[30 \mathrm{~m}, 0.25 \mathrm{~mm}$ i.d., $0.25 \mu \mathrm{m}$, film thickness (ZB-5; Phenomenex, Torrance, CA)]. The injection temperature was $270{ }^{\circ} \mathrm{C}$, and the column start temperature was $40^{\circ} \mathrm{C}$. The injection splitter (10:1) was closed for $1 \mathrm{~min}$. After $1 \mathrm{~min}$, the oven temperature was increased to $180{ }^{\circ} \mathrm{C}$ at $10{ }^{\circ} \mathrm{C} \cdot \mathrm{min}^{-1}$ and then to $290{ }^{\circ} \mathrm{C}$ at $6{ }^{\circ} \mathrm{C} \cdot \mathrm{min}^{-1}$. The interface temperature, source temperature, and ionization voltage of the mass spectrometer were $200{ }^{\circ} \mathrm{C}, 270{ }^{\circ} \mathrm{C}$, and $70 \mathrm{eV}$, respectively. Ions $\mathrm{m} / \mathrm{z} 436$ (retention time $24.68 \mathrm{~min}$ ) and $\mathrm{m} / \mathrm{z}$ 434 (retention time $24.70 \mathrm{~min}$ ) of $\left[{ }^{2} \mathrm{H}_{2}\right] \mathrm{GA}_{19}$-MeTMSi and $\mathrm{GA}_{19}$-MeTMSi, respectively, were quantified by single ion monitoring. The concentration of endogenous $\mathrm{GA}_{19}$ in each sample was determined from a calibration curve of the peak area ratios between $\mathrm{m} / \mathrm{z} 434$ and $\mathrm{m} / \mathrm{z} 436$ plotted against the ratio of $\mathrm{GA}_{19}$-MeTMSi concentration to $\left[{ }^{2} \mathrm{H}_{2}\right] \mathrm{GA}_{19}$-MeTMSi concentration. The limit of quantitation for $\mathrm{GA}_{19}$ was $0.05 \mathrm{ng}$; the calibration curve constructed ( $0.05 \mathrm{ng}$ to $\left.10 \mathrm{ng} \mathrm{GA}_{19}\right)$ was linear $\left(r^{2}=0.99\right)$. Average recovery of $\left[{ }^{2} \mathrm{H}_{2}\right] \mathrm{GA}_{19}$-MeTMSi was $58 \%$.

STATistics. The experiment was a completely randomized design with four rootstock treatments ['Royal Gala' scions on M.9, MM.106, M.793, and R.G (control) rootstocks]. Six replicate trees per rootstock were destructively measured at each of the five harvest dates. Samples from two replicate trees were pooled before hormone analysis; hence, there were only three replicates per rootstock and harvest date for all hormone data. For each harvest, data were subjected to analysis of variance (ANOVA) using the GLM procedure of SAS (Version 9.1; SAS Institute, Cary, NC). Mean separation of data with a significant ANOVA F-test $(P \leq 0.05)$ was made using the least significant difference at $P=0.05$. Allometric relationships between natural $\log (\ln )$ root dry weight and $\ln$ scion dry weight were investigated using major axis regression (Warton et al., 2006) to estimate the slope of the regression lines over two 3-month periods: December to February and February to April. The regression slopes of rootstocks were compared using the method of Warton et al. (2006).

\section{Results}

SCION GROWTH. Rootstocks did not affect the mean length or node number of the primary shoot by April (Fig. 1A-B). However, the final SCA of the primary shoot was lower on M.9 and M.793 (Fig. 1C), which reduced the final dry weight of the primary shoot stem compared with R.G (Table 1). These final differences in SCA, particularly for M.9, occurred between March and April (Fig. 1C). Rootstocks did not significantly affect the final mean internode length of the primary shoot or the number of primary shoots that ended growth early (data not shown). During January and February, there were trends $(P=0.08)$ that R.G had developed more secondary shoots than M.9, MM.106, or M.793 (Fig. 1F). By March and April, rootstocks did not significantly affect secondary shoot numbers; however, scions on M.9 had developed approximately half the number of secondary shoots than the other rootstocks (Fig. 1F). Consequently, the final mean total length and node number of the secondary shoots tended to be lower on M.9 (Fig. 1D-E). In March, 90\%, 84\%, 82\%, and 74\% $(P=0.70)$ of secondary shoots had ended extension growth for the scion on M.9, MM.106, M.793, and R.G, respectively. By April, M.9 had a lower proportion of long secondary shoots present on its scion, thereby reducing the final mean length and node number of these shoots slightly compared with R.G (data not shown). The final mean total shoot length (Fig. 1G) and dry weight of stems (Fig. 1I) was also lower for scions on M.9 than R.G. There was also a trend $(P=0.09)$ that the final total node number of the scion was lower on M.9 (Fig. 1H).

RooT GROWTH. From December to February, rootstocks did not differ in the mean total length or dry weight of the root system (Fig. 2A-B). However, root systems of invigorating rootstocks grew strongly from March to April, whereas the total length and dry weight of the M.9 root system did not greatly increase during this period (Fig. 2A-B). Consequently, mean dry weight and total length of the M.9 root system were smaller in April compared with R.G (Fig. 2A-B). The mean total dry weight of the M.793 root system was greater than the other rootstocks (Fig. 2B). For each rootstock, specific root weight (i.e., total root dry weight/total root length) steadily increased from January onward (Fig. 2C). By April, M.9 had a lower specific root weight than MM.106, M.793, and R.G (Fig. 2C). In contrast, specific root weight of M.793 was greater than the other rootstocks (Fig. 2C).

Total GROWTH PER TREe. By April, the effect of M.9 was to limit dry matter accumulation in the root, rootstock stem, and stem of the primary shoot compared with R.G, collectively lowering the mean total dry weight of the tree (Table 1). M.9 also lowered the root:scion dry weight ratio by April compared with R.G, and differences between these rootstocks were apparent after March (Fig. 2D). MM.106 did not affect the final root:scion dry weight ratio compared with R.G (Fig. 2D), but it had a lower total tree dry weight with less dry matter allocated to the leaves of the primary shoot and the rootstock stem (Table 1). Although M.793 did not affect total dry weight of the tree compared with R.G, final dry matter allocation into the root system was greater (Table 1). However, less dry matter had accumulated in the rootstock stem of M.793 and in the leaves and stem of the primary shoot (Table 1). Increased dry 

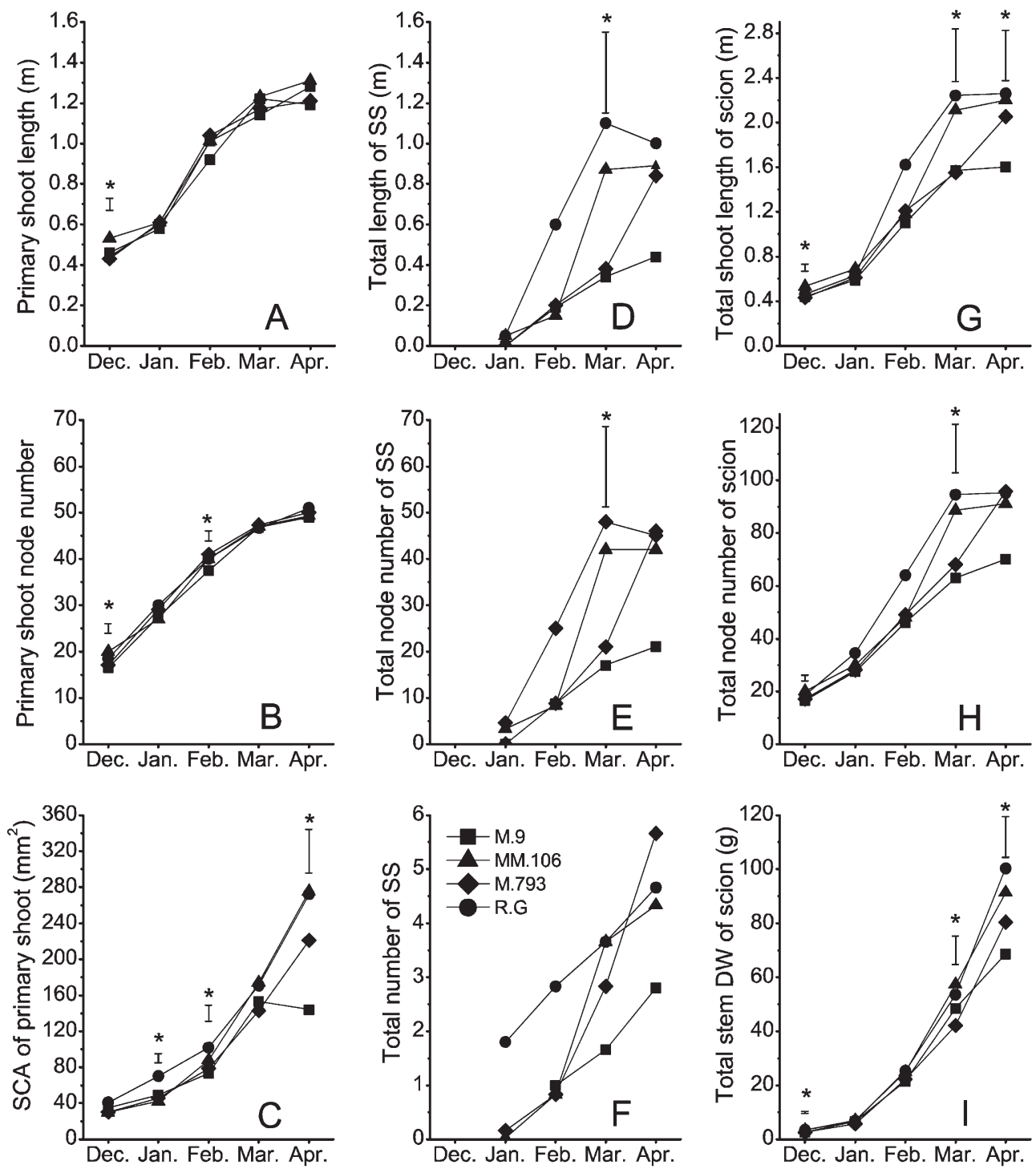

Month (2005-06)

Fig. 1. Effect of rootstocks [M.9, MM.106, M.793, and 'Royal Gala' control (R.G)] on the growth attributes of 'Royal Gala' apple scions during their first growing season (2005-2006) after spring grafting (1 Sept. 2005): (A) mean length, (B) node number, and (C) shoot cross-sectional area (SCA) of the primary shoot; (D) mean total length, (E) node number, and (F) number of secondary shoots (SS); (G) mean total shoot length, (H) node number, and (I) dry weight (DW) of stems (primary + secondary shoots) per scion. An asterisk denotes a significant analysis of variance F-test $(P \leq 0.05)$ among the rootstock treatment means for that month; the corresponding vertical bar is the least significant difference at $P=0.05$.

Table 1. Summary of the final total dry weight (DW) per tree and final DW of component tree parts for 'Royal Gala' apple trees on M.9, MM.106, M.793, and 'Royal Gala' [R.G (control)] rootstocks at the end of the first growing season (6 Apr. 2006) after spring grafting (1 Sept. 2005).

\begin{tabular}{|c|c|c|c|c|c|c|c|c|c|c|c|}
\hline \multirow[b]{2}{*}{ Rootstock } & \multicolumn{3}{|c|}{ DW rootstock (RS) } & \multicolumn{3}{|c|}{ DW primary shoot (PS) } & \multicolumn{3}{|c|}{ DW secondary shoots (SS) } & \multirow{2}{*}{$\begin{array}{c}\text { Total DW } \\
\text { of scion } \\
(\mathrm{g})\end{array}$} & \multirow{2}{*}{$\begin{array}{c}\text { Total DW } \\
\text { of tree } \\
(\mathrm{g})\end{array}$} \\
\hline & $\begin{array}{l}\text { Root } \\
(\mathrm{g})\end{array}$ & $\begin{array}{c}\text { Stem } \\
(\mathrm{g})\end{array}$ & $\begin{array}{l}\text { RS total } \\
(\mathrm{g})\end{array}$ & $\begin{array}{l}\text { PS stem } \\
(\mathrm{g})\end{array}$ & $\begin{array}{c}\text { PS leaves } \\
(\mathrm{g})\end{array}$ & $\begin{array}{l}\text { PS total } \\
(\mathrm{g})\end{array}$ & $\begin{array}{c}\text { SS stem } \\
(\mathrm{g})\end{array}$ & $\begin{array}{c}\text { SS leaves } \\
(\mathrm{g})\end{array}$ & $\begin{array}{l}\text { SS total } \\
(\mathrm{g})\end{array}$ & & \\
\hline M.9 & $25.0 \mathrm{c}^{\mathrm{z}}$ & $24.7 \mathrm{c}$ & $49.8 \mathrm{c}$ & $62.9 \mathrm{c}$ & $41.0 \mathrm{ab}$ & $103.9 \mathrm{~b}$ & $5.6 \mathrm{NS}$ & $10.3 \mathrm{NS}$ & $16.0 \mathrm{NS}$ & $119.9 \mathrm{c}$ & $169.6 \mathrm{c}$ \\
\hline MM.106 & $42.7 \mathrm{~b}$ & $28.0 \mathrm{bc}$ & $70.7 \mathrm{~b}$ & $80.0 \mathrm{ab}$ & $34.3 \mathrm{c}$ & $114.2 \mathrm{~b}$ & 11.4 & 16.7 & 28.0 & $142.3 \mathrm{ab}$ & $213.0 \mathrm{~b}$ \\
\hline M.793 & $54.8 \mathrm{a}$ & $33.0 \mathrm{~b}$ & $87.9 \mathrm{a}$ & $71.3 \mathrm{bc}$ & $36.3 \mathrm{bc}$ & $107.5 \mathrm{~b}$ & 9.0 & 16.4 & 25.4 & $132.9 \mathrm{bc}$ & $220.8 \mathrm{ab}$ \\
\hline R.G & $43.0 \mathrm{~b}$ & $42.3 \mathrm{a}$ & $85.4 \mathrm{a}$ & $88.2 \mathrm{a}$ & $43.2 \mathrm{a}$ & $131.4 \mathrm{a}$ & 12.1 & 16.0 & 28.1 & $159.6 \mathrm{a}$ & $244.9 \mathrm{a}$ \\
\hline
\end{tabular}

${ }^{\mathrm{z}}$ Within a column, means with different letters are significantly different using the least significant difference test at $P=0.05$. NS $=$ Non-significant analysis of variance F-test at $P \leq 0.05$ for column means.

weight of the root system and decreased dry weight of the primary shoot imposed by M.793 (Table 1) increased its final root:scion dry weight ratio compared with R.G (Fig. 2D).
Allometry between root And SCION. The allometric coefficients $(k)$ or slopes of fitted major axis regression lines (Fig. 3) were similar among rootstocks in either the December to 

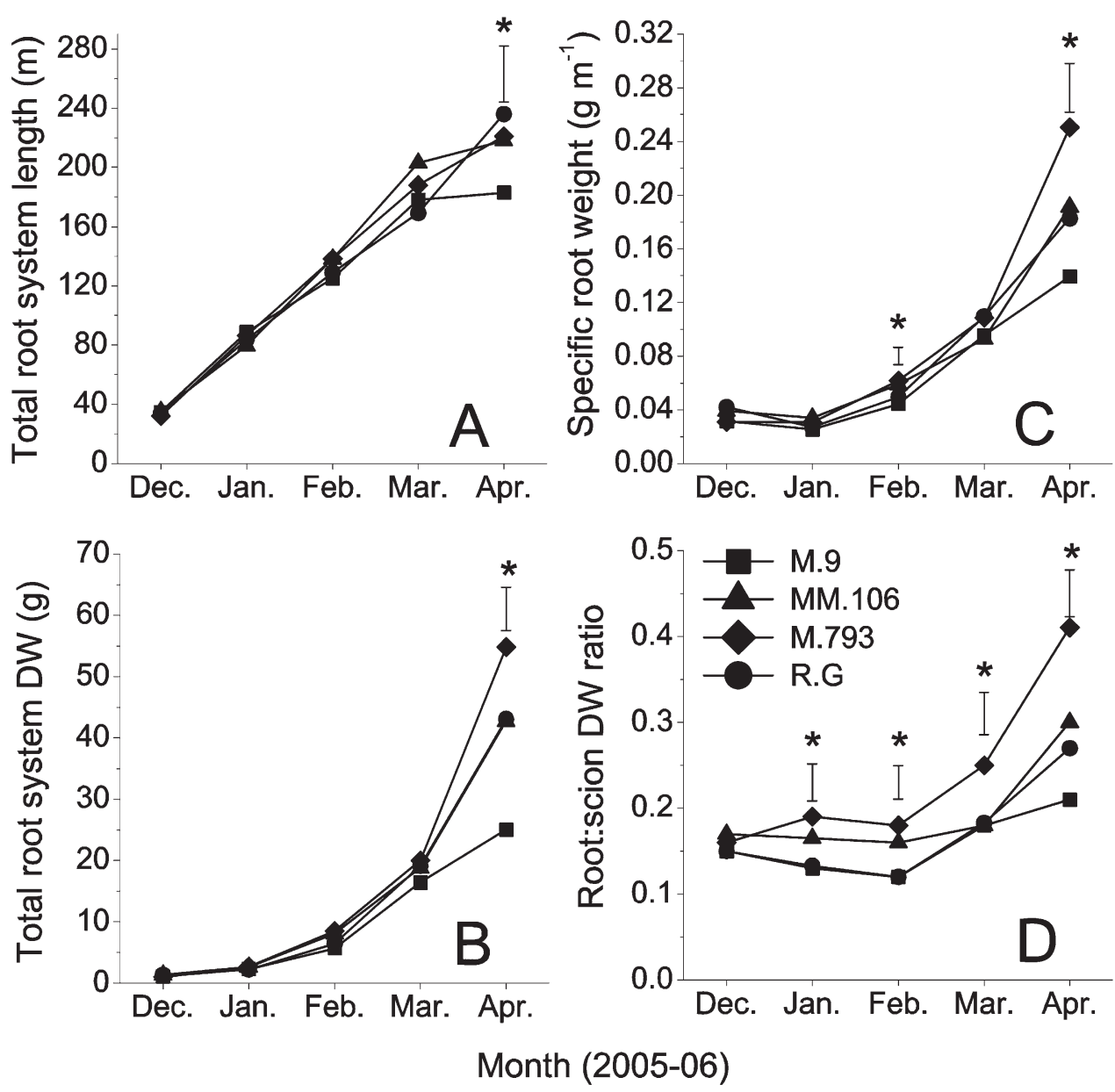

Fig. 2. Effect of rootstocks [M.9, MM.106, M.793, and 'Royal Gala' control (R.G)] on (A) the mean total length of the root system, (B) total dry weight (DW) of the root system, (C) specific weight of the root system, and (D) DW ratio between root system and the scion of composite 'Royal Gala' apple trees during their first growing season (2005-2006) after spring grafting (1 Sept. 2005). For (D), scion DW includes stems and leaves; root DW excludes the rootstock stem. An asterisk denotes a significant analysis of variance F-test $(P \leq 0.05)$ among the rootstock treatment means for that month; the corresponding vertical bar is the least significant difference at $P=0.05$.

February $\left(\chi^{2}=2.5, \mathrm{df}=3, P=0.48\right)$ or in the February to April period $\left(\chi^{2}=2.2\right.$, df $\left.=3, P=0.52\right)$ and could be estimated by a common slope in each period (Table 2). For each rootstock, $k$ was greater in February to April compared with the December to February period (Fig. 3; Table 2).

INDOLE-3-ACETIC ACID, CYTOKININS, AND BRANCHING. Rootstocks did not significantly affect the rate of IAA diffusion from the primary shoot apex throughout the growing season (data not shown). The rate of IAA diffusing from the primary shoot apex declined from January onward (Fig. 4). In December and January, volumes of xylem sap extracted from the primary shoot were insufficient for reliable detection and quantification of cytokinins or gibberellins. Therefore, these hormone data are reported only for February, March, and April. In order of most to least abundant, putative cytokinins identified within the xylem sap included ZR, IPA, 2iP, Z, 2iP ribotide, $Z$ ribotide, and a novel isopentenyl-type compound recovered as $2 \mathrm{iP}$ after incubation of the sap with alkaline phosphatase. Concentrations of $\mathrm{Z}$, cytokinin ribotides, and the novel isopentenyl-type cytokinin were very low, and rootstocks did not significantly affect the concentration of $\mathrm{Z}$, cytokinin ribotides, the isopentenyl-type compound (data not shown), IPA, or $2 \mathrm{iP}$ at any harvest date. In February, the primary shoot on M.9 contained a greater concentration of $\mathrm{ZR}$ in its xylem sap than MM.106, M.793, or R.G (Fig. 5A). In March and April, however, ZR concentration was not different among rootstocks; although in April, ZR concentration appeared to increase with increasing rootstock vigor (Fig. 5A). Interestingly, mean ZR concentration in the xylem sap of the primary shoot increased for each rootstock from February to April (Fig. 5A), whereas mean rates of IAA diffusion from the apex of the primary shoot declined during this same period (Fig. 4). Hence, a putative relationship existed whereby higher mean rates of IAA diffusion from the shoot apex appeared to correspond to lower mean concentrations of $\mathrm{ZR}$ in the xylem sap (Fig. 6B). In contrast, concentrations of IPA or 2iP declined in the xylem sap from February to April; thus, higher mean rates of IAA diffusion from the primary shoot apex appeared to correspond with higher mean concentrations of these cytokinin forms (Figs. 6A and 6C). From February to April, increases in the mean concentration of ZR in the xylem sap appeared to correspond with cumulative increases in the mean number of axillary growing points formed on the primary shoot (Fig. 6D). However, xylem sap from M.9 contained a greater concentration of $\mathrm{ZR}$ in February than the other rootstocks (Fig. 5A), but the scion on M.9 had developed a similar number of axillary growing points (i.e., spurs + secondary shoots) to MM.106, M.793, and R.G (Fig. 6D).

Gibberellins AND SHOOT TeRmination. During February, $\mathrm{GA}_{19}$ concentration in the xylem sap was unaffected by rootstock (Fig. 5B). In March, $\mathrm{GA}_{19}$ concentration was lower for M.9, MM.106, and M.793 compared with R.G (Fig. 5B). There were also trends in March that mean $\mathrm{GA}_{19}$ concentration increased with increasing rootstock vigor (Fig. 5B), and higher $\mathrm{GA}_{19}$ concentration appeared to correspond with lower mean proportions of secondary shoots on the scion that had ended extension growth $(90 \%, 84 \%, 82 \%$, and $74 \%$ for M.9, MM. 106 , M.793, and R.G, respectively). However, this effect of rootstock on shoot termination was not statistically significant $(P=$ 0.70). In April, xylem sap from M.9 contained a greater concentration of $\mathrm{GA}_{19}$ than R.G, and there were trends that $\mathrm{GA}_{19}$ concentration decreased with increasing rootstock vigor (Fig. 5B). These differences in $\mathrm{GA}_{19}$ concentration during April (Fig. 5B) occurred at a time when $100 \%$ of shoots had fully ended extension growth for the scion on each rootstock (data not shown). 


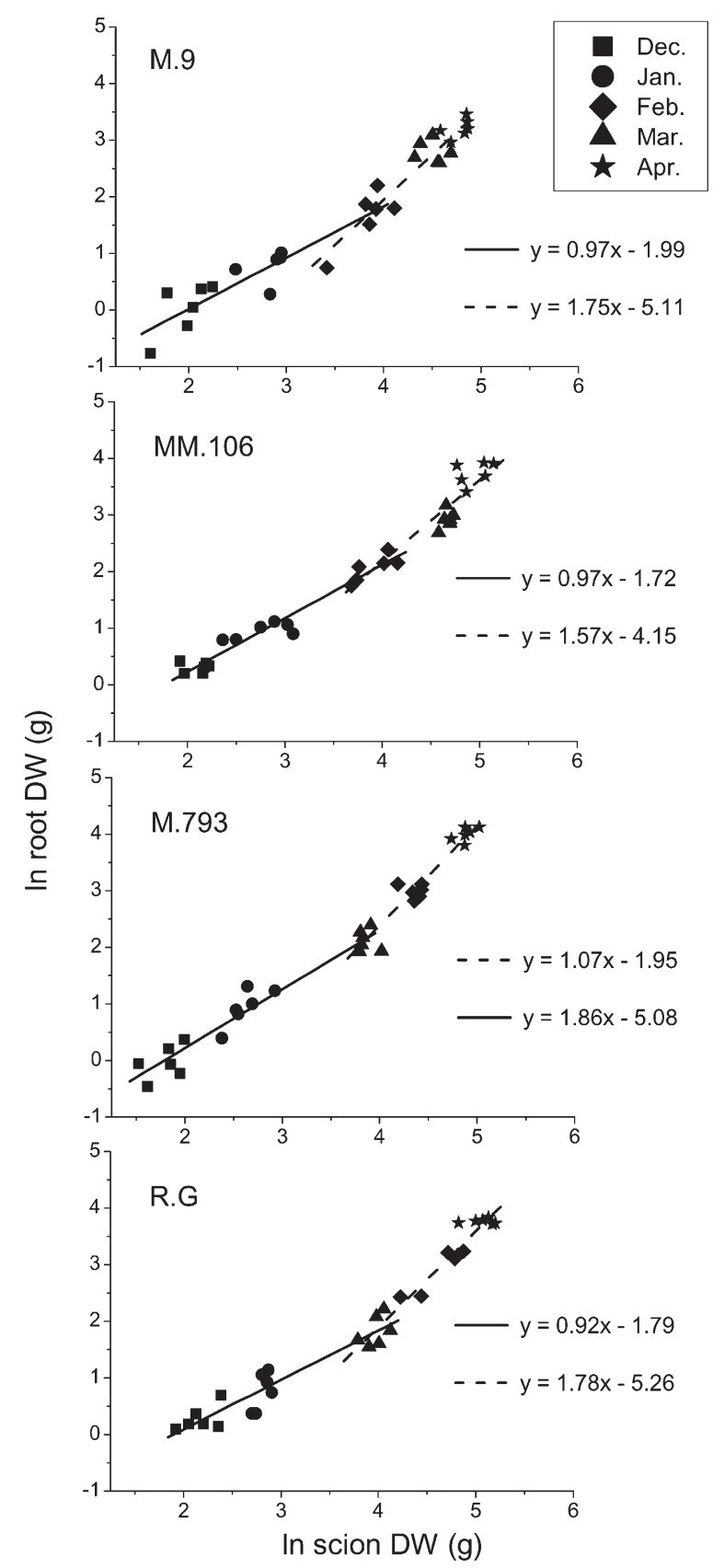

Fig. 3. Allometry between root system and scion of composite 'Royal Gala' apple trees grafted onto M.9, MM.106, M.793, and a 'Royal Gala' (R.G) rootstock control during their first growing season (2005-2006) after spring grafting (1 Sept. 2005). Fitted lines are major axis regressions. Solid and dashed lines are fitted to data for December to February and February to April, respectively. Each data point represents a single tree, and data are natural log (ln) transformed. Scion dry weight (DW) includes stems and leaves.

\section{Discussion}

Mean total shoot length and total dry weight of the scion were significantly lower on M.9 compared with the R.G rootstock control by growth cessation in April (Fig. 1G; Table 1). Hence, scion dwarfing was imposed by M.9 during the first year of growth after grafting of the composite tree. Total shoot growth of the scion was limited by M.9 (Fig. 1G) mostly because fewer secondary shoots formed compared with R.G (Fig. $1 \mathrm{~F})$, and the mean length of the secondary shoots was slightly
Table 2. Estimates of major-axis regression slopes $(k)$ and $95 \%$ confidence intervals for the allometric relationships of Figure 2 between natural $\log (\ln )$ root dry weight and ln scion dry weight during the December to February and February to April growing periods for newly grafted 'Royal Gala' apple trees on M.9, MM.106, M.793, and 'Royal Gala' [R.G (control)] rootstocks.

\begin{tabular}{lcc}
\hline Rootstock & $k$ December to February & $k$ February to April \\
\hline M.9 & $0.97(0.78,1.21)^{\mathrm{z}}$ & $1.75(1.46-2.14)$ \\
MM.106 & $0.97(0.86,1.08)$ & $1.57(1.30-1.91)$ \\
M.793 & $1.07(0.94,1.22)$ & $1.86(1.62-2.15)$ \\
R.G & $0.92(0.76,1.10)$ & $1.78(1.56-2.05)$ \\
Common slope & $0.99(0.92,1.06)$ & $1.76(1.63-1.91)$
\end{tabular}

${ }^{\mathrm{z}}$ Data in parentheses are $95 \%$ confidence intervals of the major axis regression slopes (Fig. 2).

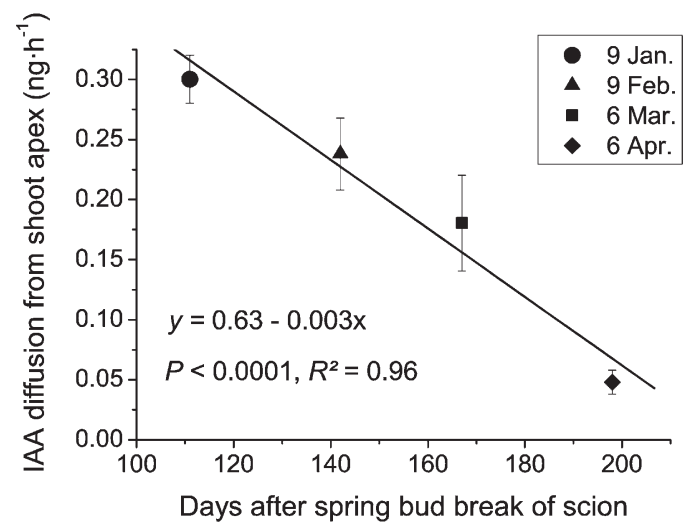

Fig. 4. Relationship between the mean concentration of endogenous indole-3acetic acid (IAA) diffusing from the primary shoot apex of 'Royal Gala' apple scions and the time from spring budbreak corresponding to the January to April growing period of the first season (2005-2006) of growth after spring grafting (1 Sept. 2005). Data for each month are the mean \pm SE of all four rootstock treatments.

shorter because of a tendency for a slightly higher proportion of secondary shoots to end extension growth early. Similarly, fewer secondary shoots formed for other scion cultivars grown on M.9 (Jaumien et al., 1993), and this rootstock increased the proportion of shoots on the scion that ended extension growth early (Robitaille and Carlson, 1976). M.9 did not affect the length of the primary shoot during the first year of growth after tree grafting (Fig. 1A), and similar results were reported by Seleznyova et al. (2008) and Tukey and Brase (1941). However, others have reported that the final length of the primary shoot was shorter on M.9 by the end of the first year of growth after grafting (Cannon, 1941; Costes et al., 2001; Rao and Berry, 1940; van Hooijdonk et al., 2010), indicating there is a degree of plasticity concerning the year when dwarfing of the primary shoot is first expressed. When tree height is unaffected by M.9 in the first year of growth after grafting (Fig. 1A), rootstock-imposed dwarfing of the primary shoot is likely to be expressed in the second growing season after increased flowering of the scion on M.9 (Seleznyova et al., 2008).

In root:shoot allometry, a $k$ greater than one indicates that dry matter accumulation is prioritized into root rather than shoot growth (Atwell et al., 1999). From February to April, $k$ greatly increased for each rootstock (Table 2; Fig. 3) because the priority of dry matter allocation increasingly favored the root system over the scion. This increase in $k$ from February 

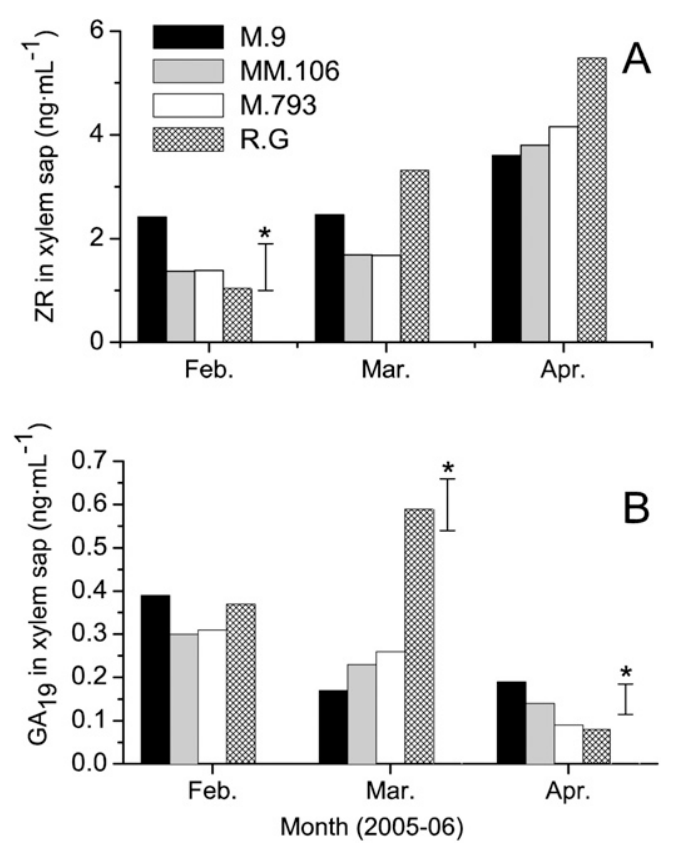

Fig. 5. Mean concentration of (A) zeatin riboside (ZR) and (B) gibberellin A19 $\left(\mathrm{GA}_{19}\right)$ in xylem sap extracted from 'Royal Gala' primary shoots on M.9, MM.106, M.793, and 'Royal Gala' [R.G (control)] rootstocks during February, March, and April of the first growing season (2005-2006) after spring grafting (1 Sept. 2005). An asterisk denotes a significant analysis of variance F-test $(P \leq 0.05)$ among the rootstock treatment means for that month; the corresponding vertical bar is the least significant difference at $P=0.05$.

(Table 2; Fig. 3) coincided with the slowing of shoot extension growth, which became apparent for M.9, MM.106, and R.G from early March onward (Fig. 1G). Similarly, Abod and Webster (1989) reported that root rather than shoot extension growth predominated from late summer onward for trees of 'Spartan' on M.9 or MM.106 in their second year of growth. The physiological mechanisms that increased $k$ from February (Fig. 3) are likely to involve signaling by endogenous hormones (Waring, 1970). Putative signaling mechanisms may exist whereby IAA transport is decreased from the shoot apex (Fig. 4) and/or in the rootstock stem during the summer (Kamboj et al., 1997), leading to increased root synthesis of some cytokinin forms including ZR (Figs. 5A and 6B). Increased ZR synthesis by the root may change the dynamics of assimilate partitioning within the composite apple tree. Evidence for this was reported for grapevines (Vitis vinifera) in which BAP applied to the root increased partitioning of ${ }^{14} \mathrm{C}$-photosynthate into the root at the expense of the shoot (Shindy et al., 1973). For apple, BAP applied to the root increased the root:shoot ratio compared with untreated seedlings (Richards, 1980). Elevated endogenous concentrations of gibberellins may also influence allometry because gibberellins applied to apple scions stimulated shoot extension growth (Luckwill and Silva, 1979) and lowered the root:shoot dry weight ratio of young 'M.26' trees (Guak et al., 2001).

The ability of exogenous gibberellins to stimulate shoot extension growth of apple shoots (Robitaille and Carlson, 1976; Sironval et al., 1962; van Hooijdonk et al., 2010) indicates endogenous gibberellins may have a role in rootstock-induced scion dwarfing. We quantified $\mathrm{GA}_{19}$ because it appeared to be an important transport form present in the xylem sap of apple
(Motosugi et al., 1996) that could be converted to bioactive $\mathrm{GA}_{1}$ (Yamaguchi, 2008) by shoot apices of the scion. In this study, M.9 had a lower concentration of $\mathrm{GA}_{19}$ in the xylem sap during March compared with the vigorous R.G rootstock control, and there were general trends that $\mathrm{GA}_{19}$ concentration increased with increasing rootstock vigor (Fig. 5B). Furthermore, the lower concentrations of $\mathrm{GA}_{19}$ measured for the more dwarfing rootstocks in March (Fig. 5B) appeared to coincide with the termination of a slightly higher percentage of secondary shoots on their scion $(90 \%, 84 \%, 82 \%$, and $74 \%$ for M.9, MM.106, M.793, and R.G, respectively). However, these differences in shoot termination among the rootstocks were not significant $(P=0.70)$.

In a previous study, we found that scions on M.9 had a higher proportion of shoots that ended extension growth early compared with more invigorating rootstocks, and this effect of M.9 was largely prevented by applying gibberellins to the scion (van Hooijdonk et al., 2010). Similar to M.9, restricting basipetal IAA transport of vigorous rootstocks, by applying 1-N-naphthylphthalamic acid (NPA) to the rootstock stem, caused shoots on the scion to end extension growth; however, shoot growth could be reinstated by applying gibberellin to the scion (van Hooijdonk et al., 2010). Therefore, decreased basipetal transport of IAA imposed by NPA, and possibly by the stem tissue of M.9 (Kamboj et al., 1997), may limit the amount of rootproduced gibberellins that is synthesized and supplied to the scion for shoot extension growth. To confirm this hypothesis, it would be necessary to demonstrate that the M.9 rootstock limits the basipetal transport of radiolabeled IAA to the root, that a limited IAA supply at the root lowers the amount of rootproduced gibberellins supplied to shoot apices of the scion in the xylem sap, and that these events coincide with earlier cessation of shoot extension growth for the scion on M.9. Although this study provides new evidence that dwarfing rootstocks can lower the concentration of root-produced $\mathrm{GA}_{19}$ in the xylem sap of the scion (Fig. 5B), in further studies, it will be important to ascertain whether other biologically important gibberellin forms are present in the xylem sap of different sizecontrolling rootstocks and whether rootstocks preferentially transport different gibberellins. In addition, a limitation of our hormone data (measured as nanograms per milliliter of xylem sap) was that it did not take into account potential rootstock differences in xylem sap flow and thus rates of hormone delivery to the scion.

It has been known for some time that ABA concentration within the xylem sap of the scion is higher for trees on dwarfing rootstocks (Kamboj et al., 1999b). Injection of abscisic acid (ABA) into the xylem sap of composite apple trees on M.9, M.7, or MM.111 caused the primary shoot to cease growth, although trees on the more dwarfing rootstocks ended shoot extension growth sooner after ABA treatment. However, injection of $\mathrm{GA}_{3}$ into the xylem sap increased shoot extension growth markedly more as rootstock vigor decreased (Robitaille and Carlson, 1971). A balance of both root-produced gibberellin (promoter) and abscisic acid (inhibitor) could therefore interact to impose earlier shoot termination of the scion on M.9.

Lockard and Schneider (1981) hypothesized that reduced basipetal transport of IAA within the phloem of the rootstock stem to the root system may limit the synthesis of root-produced cytokinins and their consequent transport to the scion. However, restricting basipetal transport of IAA from shoot to root, by using shoot decapitation and/or NPA, increased cytokinin 

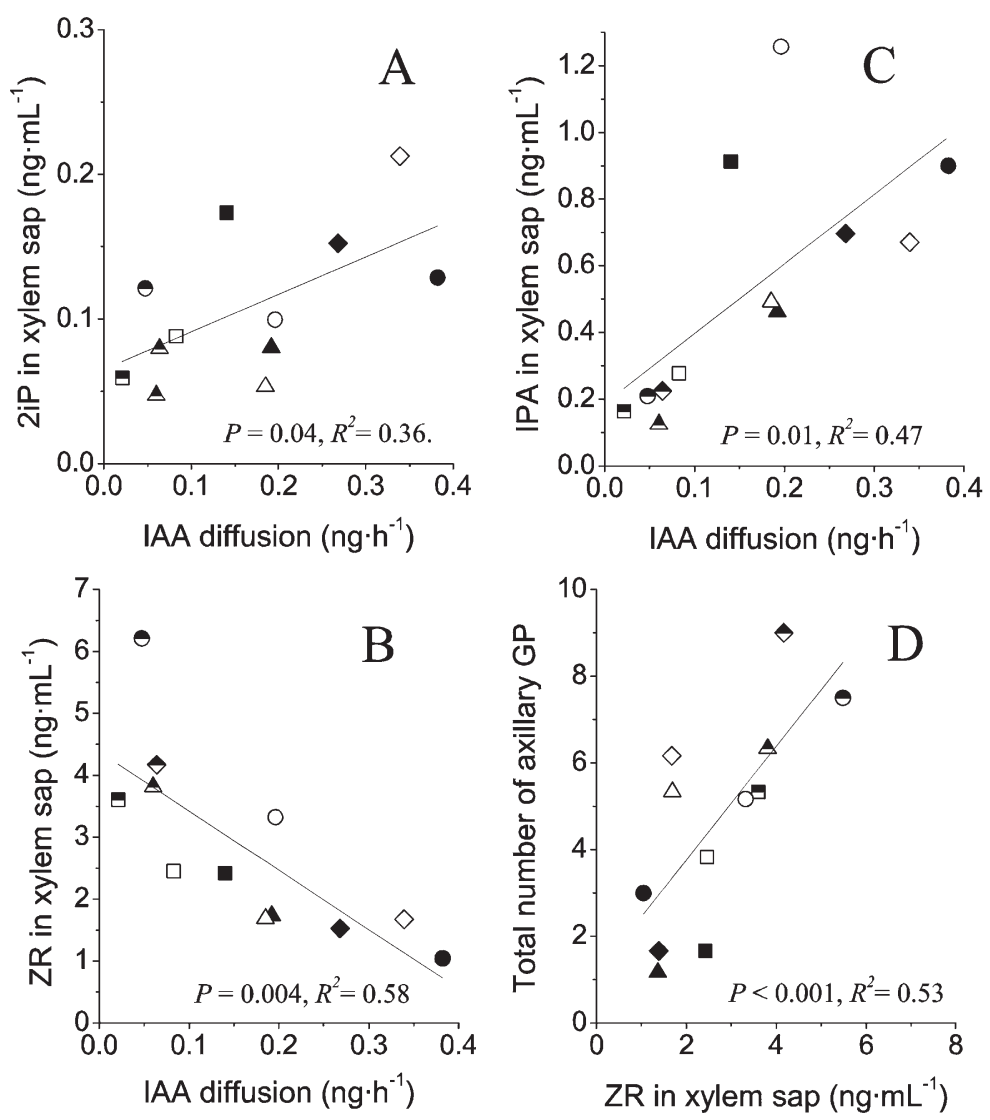

Fig. 6. Relationships during the February to March growing period between the mean concentration of indole-3acetic acid (IAA) diffusing from the shoot apex of 'Royal Gala' primary shoots and the mean concentration of (A) isopentenyladenine (2iP), (B) zeatin riboside (ZR), and (C) isopentenyladenosine (IPA) in the xylem sap of the primary shoot; and (D) the mean concentration of ZR in the xylem sap of the primary shoot and the mean total number of axillary growing points (GP) formed per scion during its first growing season (2005-2006) after spring grafting (1 Sept. 2005) onto M.9, MM.106, M.793, and 'Royal Gala' [R.G (control)] rootstocks. GP are defined as the total number of spurs plus secondary shoots formed on the primary shoot.
BAP applied to young apple scions stimulated axillary buds along the primary shoot to break and form secondary shoots (van Hooijdonk et al., 2010; Williams and Stahly, 1968). Interestingly, there was a trend $(P=0.08)$ that fewer secondary shoots had formed for the scion on M.9 in January (Fig. 1F), suggesting that endogenous cytokinins were limiting axillary bud outgrowth. Unfortunately, it could not be ascertained whether M.9 lowered cytokinin concentration in the xylem sap at this critical time of branch formation because insufficient sap was extractable from the scion. Nevertheless, there were trends from February onward for the mean concentration of ZR to increase in the xylem sap of each rootstock treatment, which appeared to coincide with cumulative increases in the mean number of axillary growing points formed on the primary shoot (Fig. 6D). However, xylem sap from M.9 contained a significantly higher concentration of ZR in February compared with R.G (Fig. 5A), but the primary shoot on M.9 had developed a similar number of axillary growing points (Fig. 6D). Thus, the development of axillary growing points for M.9 was not explained satisfactorily by ZR concentration alone and may have involved other hormonal substances transported in the xylem sap.

The novel isopentenyl-type compound measured in this study was also present in kiwifruit (Actinidia deliciosa) (Woolley and Currie, 2006); its presence in apple suggests there might be important cytokinin forms present in xylem sap of apple trees that are yet to be identified. Hydroxylated derivatives of benzyladenine (topolins) could be important candidates because the meta-topolin form has high bioactivity (Mok et al., 2005). Identification of strigolactones in pea (Pisum sativum), and demonstration of their role as an inhibitor of axillary bud outgrowth (Gomez-Roldan et al., 2008), also opens new possibilities that branching of apple trees is not regulated solely by interactions between shoot-derived IAA and rootproduced cytokinins.

\section{Literature Cited}

Abod, S.A. and A.D. Webster. 1989. Root and shoot growth of newly transplanted apple trees as affected by rootstock cultivar, defoliation and time after transplanting. J. Hort. Sci. 64:655-666.

Atkinson, C.J., M.A. Else, L. Taylor, and C.J. Dover. 2003. Root and stem hydraulic conductivity as determinants of growth potential in grafted trees of apple (Malus pumila Mill.). J. Expt. Bot. 54:12211229.

Atwell, B., P. Kriedemann, and C. Turnbull. 1999. Plants in action. Macmillan, South Yarra, Australia. 
Bangerth, F., C.J. Li, and J. Gruber. 2000. Mutual interaction of auxin and cytokinins in regulating correlative dominance. J. Plant Growth Regul. 32:205-217.

Bollard, E.G. 1953. The use of tracheal sap in the study of apple tree nutrition. J. Expt. Bot. 4:363-368.

Bulley, S., F. Wilson, P. Hedden, A. Phillips, S. Croker, and D. James. 2005. Modification of gibberellin biosynthesis in the grafted apple scion allows control of tree height independent of the rootstock. Plant Biotechnol. J. 3:215-223.

Cannon, H.B. 1941. Studies in the variation of nursery fruit trees on vegetatively raised rootstocks. J. Pomol. 19:2-32.

Costes, E., J. Salles, and G. Garcia. 2001. Growth and branching patterns along the main axis of two apple cultivars grafted on two different rootstocks. Acta Hort. 732:131-139.

Croker, S., P. Hedden, J. Lenton, and J. Stoddart. 1990. Comparison of gibberellins in normal and slender barley seedlings. Plant Physiol. 94:194-200.

Crozier, A., K. Loferski, J.B. Zaerr, and R. Morris. 1980. Analysis of picogram quantities of indole-3-acetic acid by high performance liquid chromatography-fluorescence procedures. Planta 150:366-370.

Currie, M.B. 1997. Source-sink relationships in kiwifruit: Carbohydrate and hormone effects on fruit growth at the cell, organ and whole plant level. PhD diss., Massey Univ., Palmerston North, New Zealand.

Fontana-Degradi, C. and C. Visai. 1978. Correlation between growth of apple shoots and content of gibberellin-like substances. Acta Hort. 80:63-66.

Gomez-Roldan, V., S. Fermas, P.B. Brewer, V. Puech-Pages, E. Dun, J. Pillot, F. Letisse, R. Matusova, S. Danoun, J. Portais, H. Bouwmeester, G. Becard, C. Beveridge, C. Rameau, and S. Rochange. 2008. Strigolactone inhibition of shoot branching. Nature 455:189-194.

Guak, S., D. Neilson, and N.E. Looney. 2001. Growth, allocation of N and carbohydrates, and stomatal conductance of greenhouse grown apple treated with prohexadione-Ca and gibberellins. J. Hort. Sci. Biotechnol. 76:746-752.

Ibrahim, I. and M. Dana. 1971. Gibberellin-like activity in apple rootstocks. HortScience 6:541-542.

Jaumien, F., B. Czarnecki, and T. Mitrut. 1993. Very similar effects of a mixture of $\mathrm{GA}_{3}$ and $\mathrm{BA}$ (6-benzylaminopurine) and of $\mathrm{GA}_{4+7}$ and BA on branching of some apple cultivars in nursery. Acta Hort. 329: $35-42$.

Jones, O.P. 1973. Effects of cytokinins in xylem sap from apple trees on apple tree growth. J. Hort. Sci. 48:181-188.

Jones, O.P. and H.J. Lacey. 1968. Gibberellin-like substances in the transpiration stream of apple and pear trees. J. Expt. Bot. 19:526-531.

Kamboj, J.S., P.S. Blake, J. Quinlan, and D. Baker. 1999a. Identification and quantitation by GC-MS of zeatin and zeatin riboside in xylem sap from rootstock and scion of grafted apple trees. J. Plant Growth Regul. 28:199-205.

Kamboj, J.S., G. Browning, P.S. Blake, J.D. Quinlan, and D.A. Weaver. 1999b. GC-MS-SIM analysis of abscisic acid and indole3 -acetic acid in shoot bark of apple rootstocks. J. Plant Growth Regul. 28:21-27.

Kamboj, J.S., G. Browning, J. Quinlan, P.S. Blake, and D. Baker. 1997. Polar transport of [3H]-IAA in apical shoot segments of different apple rootstocks. J. Hort. Sci. 72:773-780.

Kender, W.J. and S. Carpenter. 1972. Stimulation of lateral bud growth of apple trees by 6-benzylaminopurine. J. Amer. Soc. Hort. Sci. 97: 377-380.

Li, C.J. and F. Bangerth. 1999. Autoinhibition of indoleacetic acid transport in the shoot of two-branched pea (Pisum sativum) plants and its relationship to correlative dominance. Physiol. Plant. 106:415-420.

Lockard, R.G. and G.W. Schneider. 1981. Stock and scion relationships and the dwarfing mechanism in apple. Hort. Rev. (Amer. Soc. Hort. Sci.) 3:315-375.

Luckwill, L.C. and J.M. Silva. 1979. The effects of daminozide and gibberellic acid on flower initiation, growth and fruiting of apple cv 'Golden Delicious'. J. Hort. Sci. 54:217-223.
MacDonald, E.M.S., D.E. Akiyoshi, and R.O. Morris. 1981. Combined HPLC-radioimmunoassay for cytokinins. J. Chromatography 214: 101-109.

Mok, M.C., R.C. Martin, P.I. Dobrev, R. Vankova, P. Shing Ho, K. Yonekura-Sakakibara, H. Sakakibara, and D.W.S. Mok. 2005. Topolins and hydroxylated thidiazuron derivatives are substrates of cytokinins O-glucosyltransferase with position specificity related to receptor recognition. J. Plant Growth Regul. 137:1057-1066.

Motosugi, H., T. Nishijima, N. Hiehata, M. Koshioka, and A. Sugiura. 1996. Endogenous gibberellins in the xylem exudate from apple trees. Biosci. Biotechnol. Biochem. 60:1500-1502.

Popenoe, J. and B.H. Barritt. 1988. Branch induction by growth regulators and leaf removal in 'Delicious' apple nursery stock. HortScience 23:859-862.

Rao, Y.V. and W.E. Berry. 1940. The carbohydrate relations of a single scion variety grafted onto Malling rootstocks IX and XIII. A contribution to the physiology of dwarfing. J. Pomol. 18:193-224.

Richards, D. 1980. Root-shoot interactions: Effects of cytokinin applied to the root and/or shoot of apple seedlings. Sci. Hort. 12: 143-152.

Robitaille, H. and R. Carlson. 1971. Response of dwarfed apple trees to stem injections of gibberellic and abscisic acids. HortScience 6:539-540.

Robitaille, H. and R. Carlson. 1976. Gibberellic and abscisic acid-like substances and the regulation of apple shoot extension. J. Amer. Soc. Hort. Sci. 101:388-392.

Seleznyova, A.N., D.S. Tustin, and T.G. Thorp. 2008. Apple dwarfing rootstocks and interstocks affect the type of growth units produced during the annual growth cycle: Precocious transition to flowering affects the composition and vigour of annual shoots. Ann. Bot. (Lond.) 101:679-687.

Shindy, W.W., W.M. Kliewer, and R.J. Weaver. 1973. Benzyladenineinduced movement of ${ }^{14} \mathrm{C}$-labeled photosynthate into roots of Vitis vinifera. Plant Physiol. 51:345-349.

Sironval, C., H. Clusters, and M.R. Wolwertz. 1962. The effect of gibberellin on growth and branching of apple trees, variety 'Golden Delicious'. Gartenbauwissenschaft 27:295-302.

Tromp, J. and J.C. Ovaa. 1994. Spring cytokinin composition of xylem sap of apple at two root temperatures. Sci. Hort. 57:1-6.

Tukey, H.B. and K.D. Brase. 1941. Similarity in the nursery of several Malling apple stock-and-scion combinations which differ widely in the orchard. Proc. Amer. Soc. Hort. Sci. 39:245-246.

van Hooijdonk, B.M., D.J. Woolley, I.J. Warrington, and D.S. Tustin. 2010. Initial alteration of scion architecture by dwarfing apple rootstocks may involve shoot-root-shoot signalling by auxin, gibberellin and cytokinin. J. Hort. Sci. Biotechnol. 85:59-65.

Waring. 1970. Growth and its coordination in trees, p. 1-21. In: Luckwill, L.C., and C.V. Cutting (eds.). Physiology of tree crops. Academic Press, London, UK.

Warton, D.I., I.J. Wright, D.S. Falster, and M. Westoby. 2006. Bivariate line-fitting methods for allometry. Biol. Rev. Camb. Philos. Soc. 81:259-291.

Weiler, E.W. 1980. Radioimmunoassay for trans-zeatin and related cytokinins. Planta 149:155-162.

Wertheim, S.J. and E.N. Estabrooks. 1994. Effect of repeated sprays of 6-benzyladenine on the formation of sylleptic shoots in apple in the fruit tree nursery. Sci. Hort. 60:31-39.

Williams, M.W. and E.A. Stahly. 1968. Effect of cytokinins on apple shoot development from axillary buds. HortScience 3:68-69.

Woolley, D.J. and M.B. Currie. 2006. Interactions between cytokinin active substances and fruit growth of Actinidia deliciosa (green kiwifruit) and Actinidia chinensis selection. Acta Hort. 727:203208.

Yadava, U.L. and R.G. Lockard. 1977. Abscisic acid and gibberellin in three ungrafted apple (Malus sylvestris) rootstock clones. Physiol. Plant. 40:225-229.

Yamaguchi, S. 2008. Gibberellin metabolism and regulation. Annu. Rev. Plant Biol. 59:225-251. 